\title{
Prediction of the Distortions for a 6061 Aluminium Alloy Plate during Quenching Process by Using Mathematical Modelling
}

\author{
Marin PETRE \\ ALRO SA, Romania, mapetre@alro.ro \\ Maria STOICANESCU \\ Transilvania University of Brasov, Romania, stoican.m@unitbv.ro \\ Nicușor Constantin DRĂGHICI \\ ALRO SA, Romania, cdraghici@alro.ro \\ Valeriu ANDREI \\ ALRO SA, Romania, vandrei@alro.ro
}

\begin{abstract}
Quenching of aluminium alloys is a complex thermo-mechano-metallurgical problem due to high non-linearity and the multiphysics character. High residual stresses and distortions are determined by the transient heat conduction problem, plastic behaviour and metallic phase transformations of the aluminium alloy plates during the quenching process. A mathematical model for the structural stresses and distortions was developed and implemented by using ANSYS finite element software. The phase transformations that occur during quenching were not taken into account. The phase transformation problem that occurs during quenching was mathematical modelled through correlation of the heat transfer coefficients with the results obtained for the temperature evolution. Numerical examples are presented for a 6061 aluminium alloy plate with dimensions of $100 \times 1500 \times 3000 \mathrm{~mm}$. The causes of distortion during quenching process are analysed using the simulation results. The computer modelling offers a support in the understanding the behaviour of the distortions in aluminium alloy plates during quenching and a better control of the process.
\end{abstract}

\section{Keywords}

ANSYS, spray quenching, distortion, 6061 aluminium alloy

\section{Introduction}

The precipitation hardening is one of the most used mechanisms for increase the strength of the aluminium alloys. The only heat-treatable aluminium alloys are those belonging to the $2 \mathrm{xxx}, 6 \mathrm{xxx}$ and $7 x x x$ series. The 6061 aluminium alloy is one of the most common alloys used in medium to high strength aerospace applications.

The solution for obtain the high-strength aluminium alloys is the quenching or a rapidly cooling, but in same time the quenching causes high residual stresses and distortions of the material $[1,2]$. The aluminium alloy plates are quenched by immersion into a liquid, spraying with a liquid or by blowing a pressurized gas. Immersion quenching was for a long time the most used industrial quenching technique. Today, the most popular technique is spray quenching, which provide a better control of the process. However, in the near future, the gas quenching is likely to become the most widely used technique due to the ease of control on heat transfer, distortion and residual stresses [3].

When the cooling process starts, the material temperature is high, generally in the range of 400 to $550{ }^{\circ} \mathrm{C}[4]$.

The quenching starts from the outside of the material to the inside with contraction and hardening, which causes internal compressive stresses which will be balanced by the external tensile stresses [5]. The high residual stresses cause changes in the size and dimensional shape of aluminium alloy plates, causing their distortion, which can be concave or convex, or even sinusoidal for the small thicknesses [6]. However, the shape and dimensions of the quenched plate can be corrected through the controlled stretching operation which reduces or eliminates the high residual stresses [7].

Most of the published works on quenching aluminium alloy plates are made by engineers rather than academia, and have as their subject quenching by immersion. The subject of spray quenching, also 
discussed in this paper, was discussed by specialists in a few works [8]. Thus, the object of this work, a 6061 aluminium alloy plate, was obtained by water spray quenching.

A rigorous mathematical formulation of the problem requires a totally coupled thermo-mechanomicrostructural model. A commonly accepted incorporation of the phase transformations in such a coupled theory was not made so far for the quenching by water spraying [9].

In this study, the structural stresses due to solid thermal effects were studied by using ANSYS finite element software. The temperature values obtained from the heat problem was used as the input data in the structural problem. Considering the mathematical model developed in earlier work [10], it was succeeded the prediction of the distortions after quenching for a 6061 aluminium alloy plate.

\section{The Mathematical Model}

The developed mathematical model is presented in detail in previous work [10]. The geometrical model was represented by a 6061 aluminium alloy plate with the dimensions $100 \times 1500 \times 3000 \mathrm{~mm}$. For the properties of the aluminium alloy plate were used data taken from academic literature [11] and standards [12]. Also, some properties of the plate were interpolated by using the least square method [13]. The main equations of the mathematical model, in our case the transient heat transfer problem is already implemented in ANSYS software, the user just need to choose the type of problem.

The initial condition for the heat transfer problem of the 6061 aluminium alloy plate was:

$$
T_{\text {ini }}=550^{\circ} \mathrm{C} \text {, when } t=0 \mathrm{~s}
$$

The boundary condition for all surfaces of the aluminium plate was:

$$
-\boldsymbol{n} \cdot(-k \nabla T)=q(P, t)
$$

where: $k$ - thermal conductivity of the aluminium alloy plate,

$T$ - temperature;

$q$ - heat flux coefficient dependent on the position of point $P$ on the surface of the plate and the time $t$.

The heat transfer coefficients used were developed for cases with normal coolant supply pressures at the spray nozzle.

For prediction of the distortions of the aluminium alloy plate during quenching process, the temperature values resulted from the heat transfer problem were used as the input data in the structural problem.

The thermal strain depends in our problem only on the temperature, $T$, the initial temperature, $T_{\text {inis }}$ and the thermal expansion vector, $\alpha$ :

$$
\varepsilon_{t h}=\alpha\left(T-T_{\text {ini }}\right)
$$

For the structural problem, the zero state was considered as the initial state. Consequently the strain was consisted only of elastic $\left(\varepsilon_{e l}\right)$ and thermal $\left(\varepsilon_{t h}\right)$ contributions:

$$
\varepsilon=\varepsilon_{e l}+\varepsilon_{t h}
$$

The stress was associated to the strain by:

$$
\sigma=E \varepsilon
$$

The plate was "fixed" on the bottom in the four corners (points) on the transversal direction and "free" in the plane area.

\section{Experimental}

The solution heat treatment and quenching process of the 6061 aluminium alloy plates were performed on the special equipment for the research of the aluminium alloy quenching process (Figure 1).

The independent equipment for the research of aluminium alloy quenching process is provided with the latest technology and commissioned in January 2019 into R\&D Department of the ALRO plant in Romania. 


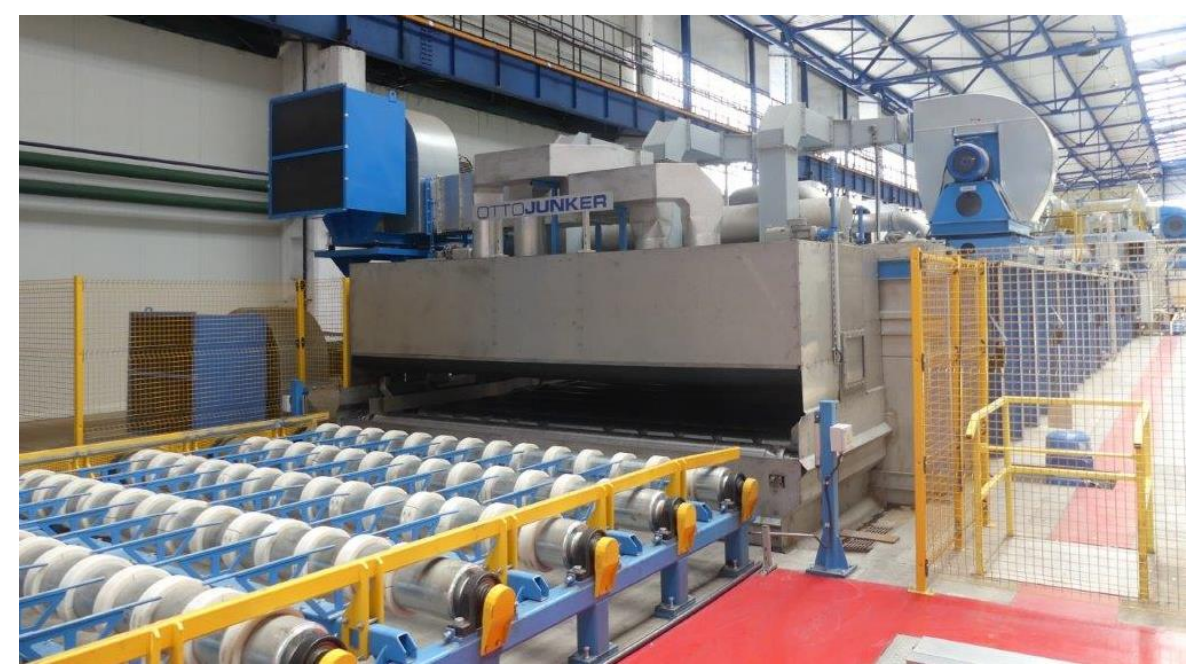

Fig. 1. The independent equipment for the research of aluminium alloy quenching process

The industrial tests were performed on 6061 aluminium alloy plates. The aluminium alloy plates were obtained by hot rolling from a cast slab.

During the solution heat treatment, the plates remain in the furnace for a certain period of time and at a certain temperature depending on their thickness and the alloy type. When this period ends, the furnace door opens and the plates exit from furnace directly in the quenching area. The main parameters during quenching are the quench speed and the spray flow on the bottom and top of the plates.

It is known that a fast cooling leads to high residual stresses and a pronounced distortion of the plate, while a slow cooling has an negative effect on the mechanical properties, because in the centre of the plate will not be quenched fast enough and therefore the plate will have a low strength and hardness. Also, the plates can be easily distorted after cutting or other finishing steps, such as machining, due to internal stresses accumulated during the quenching process $[14,15]$.

Through all the experiments and simulations performed, it was tried to find the optimal correlation between the quenching parameters and the properties of the plates requested by customers.

After the quenching process and before the stretching operation, the distortion of the plates was manually measured for each plate on the transverse and longitudinal direction.

\section{Results. Discussion}

All the simulations were run using the commercial finite element software ANSYS Discovery AIM 19.0.

Figure 2 shows the evolution of the plate distortion on the $\mathrm{Z}$ direction or on the thickness direction, normal on the XY plane determined by the length and width of the plate. The evolution of the displacement on $\mathrm{Z}$ direction is presented from the moment when the plate enters in the quenching area $(t=0 \mathrm{~s})$ until the complete exit from the quenching area $(t=45 \mathrm{~s})$.

From the analysis of the evolution of the displacement it is observed that it increases as the plate enters in the quenching (Figure $2, b-e$ ), reaches its maximum value somewhere in the interval $25-30 \mathrm{~s}$ (Figure $2, f-g$ ) and then decreases (Figure 2, $h-i$ ), so that in the end it remains at approx. $8 \mathrm{~mm}$ (Figure $2, j)$.

Figure 3 shows the evolution of the maximum values reached by the displacement on $\mathrm{Z}$ direction during the quenching. By using the least square method, the trend line equation was also drawn and the equation was displayed and the $R$-squared value.

From the analysis of the numerical results obtained, the maximum value for displacement on $\mathrm{Z}$ direction is reached at time $t=26.4 \mathrm{~s}$, when displacement is $15.52 \mathrm{~mm}$.

The validation of the results is difficult to achieve considering that in reality even for identical plates as chemical composition and dimensions the flatness is different. But, the results obtained together with the regression equation can help us in correlating the flatness of the plates with the quenching parameters or can provide us with information about the effect that changing certain parameters may have. 


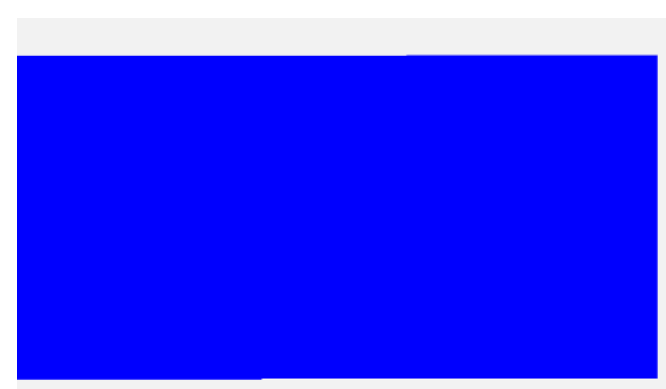

a. $t=0 \mathrm{~s}$

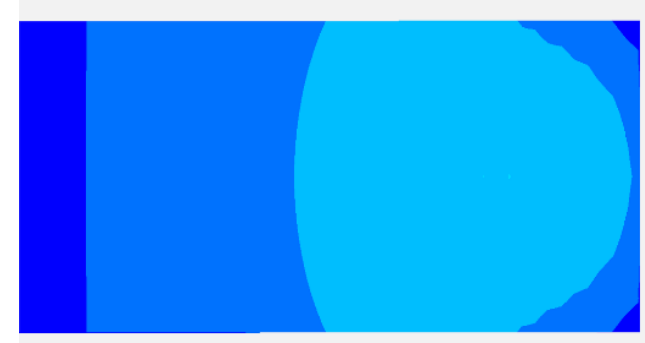

c. $t=10 \mathrm{~s}$

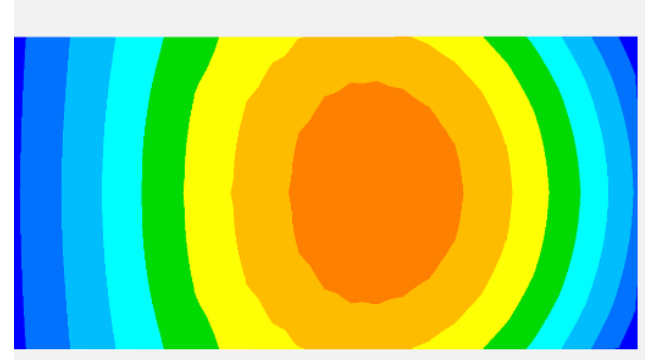

e. $t=20 \mathrm{~s}$
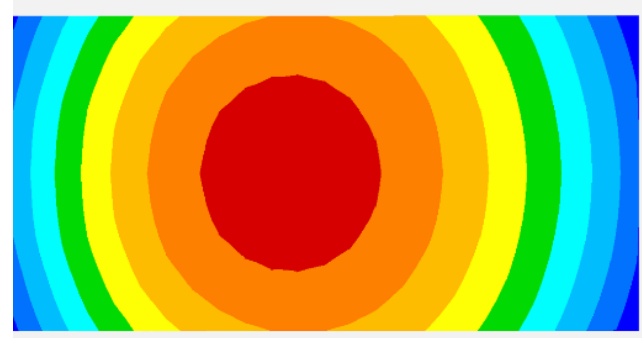

g. $t=30 \mathrm{~s}$

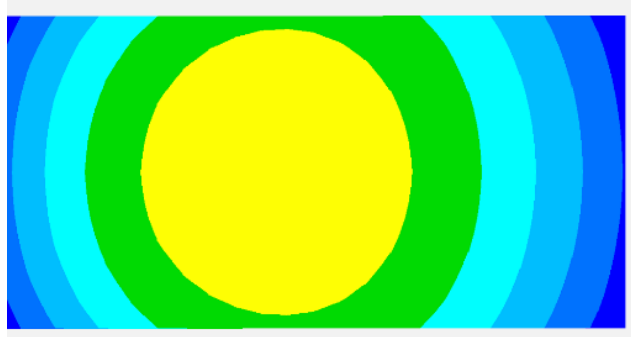

i. $\quad t=40 \mathrm{~s}$
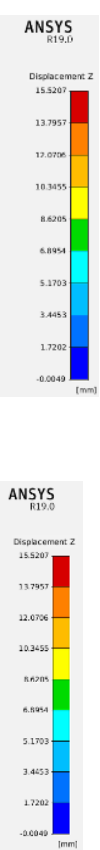

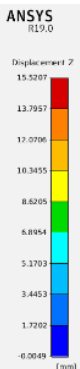

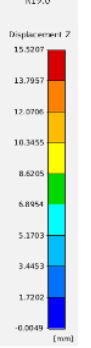

ANSYS
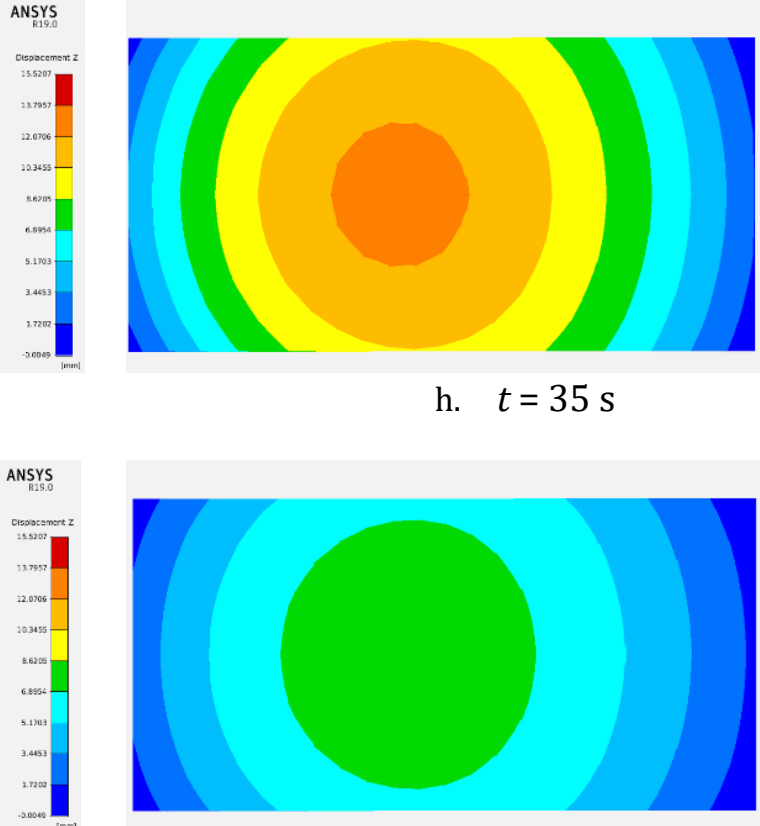

j. $\quad t=45 \mathrm{~s}$

b. $t=5 \mathrm{~s}$

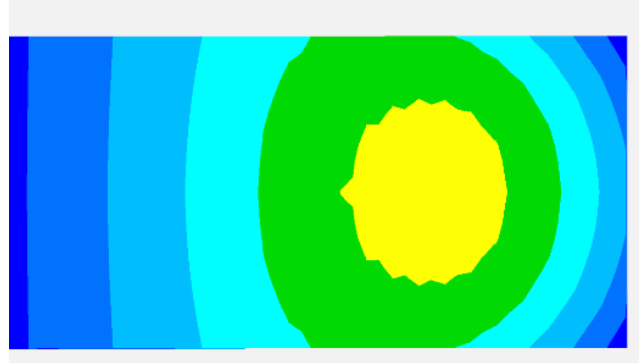

d. $\quad t=15 \mathrm{~s}$
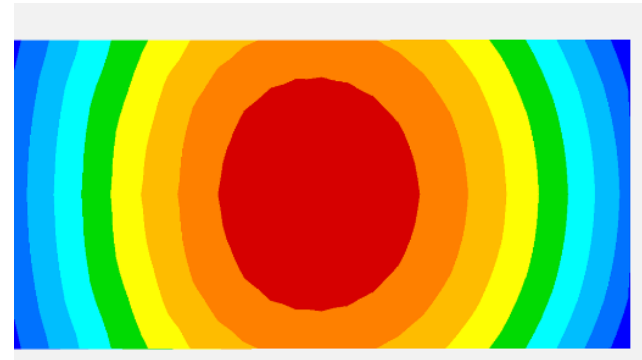

f. $t=25 \mathrm{~s}$

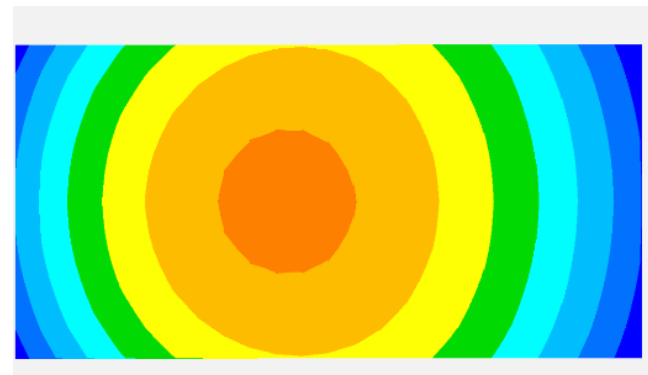

h. $t=35 \mathrm{~s}$
ANSYS

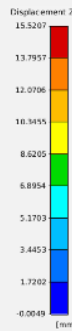

ANSYS

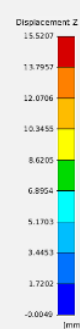

ANSYS
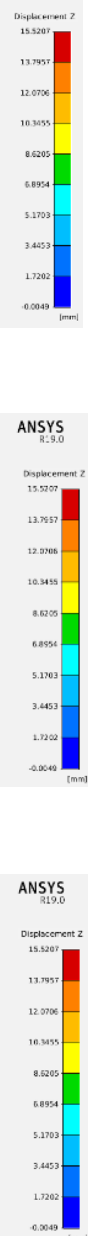

Fig. 2. The evolution of displacement on $\mathrm{Z}$ direction for a 6061 aluminium alloy plate - numerical results 


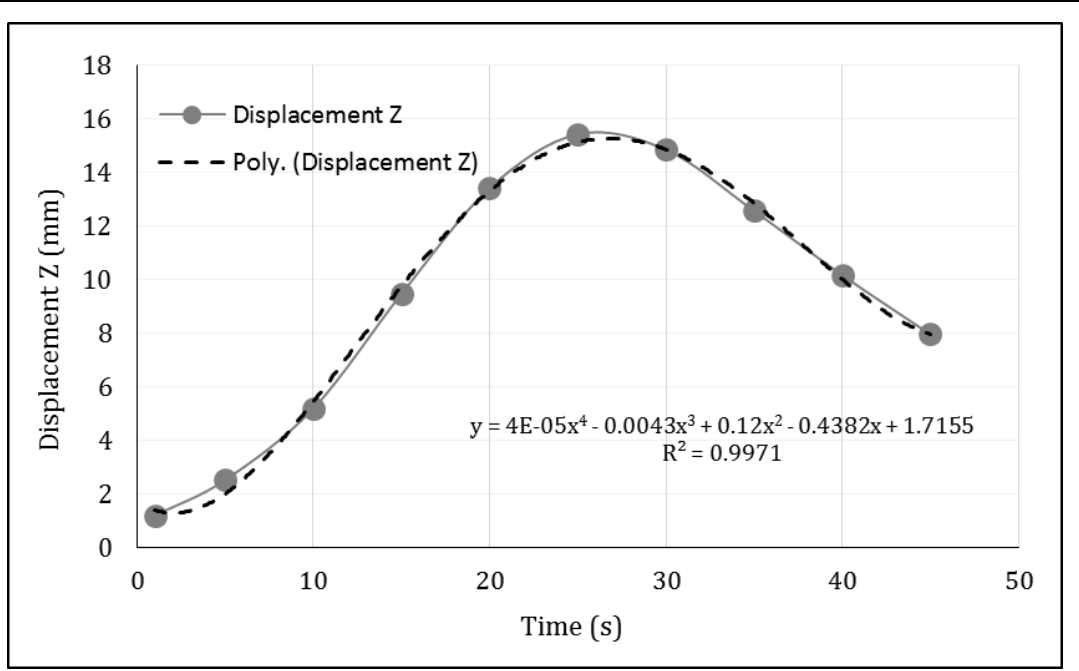

Fig. 3. The evolution of the maximum values for displacement on $\mathrm{Z}$ direction for a 6061 aluminium alloy plate - numerical results

For example, for a higher quenching speed, the quenching time will be shorter and implicitly a higher distortion for the plate. In the future research works we will study the correlation of the main quenching parameters with the flatness and residual stresses of the aluminium alloy plates.

\section{Conclusions}

The results obtained with a mathematical model implemented by using ANSYS software was presented. The object of the simulations was a 6061 aluminium alloy plate, obtained by water spray quenching.

The numerical study provides valuable information concerning with the evolution of flatness during the quenching process.

The maximum value for displacement on $\mathrm{Z}$ direction was reached at time $t=26.4 \mathrm{~s}$, when displacement was $15.52 \mathrm{~mm}$.

Future work will focus for study of the correlation of the main quenching parameters with the flatness and residual stresses for the aluminium alloy plates.

\section{Acknowledgements}

Part of the cost of the industrial equipment used to obtain the results presented in this work was funded by European Union through Competitiveness Operational Programme, Priority Axis 1 Research, Technological Development and Innovation, within the project "Investments in the R\&D Department of ALRO aiming at improving the research infrastructure for the aluminium alloy heat treated plates with high qualification industrial applications", based on the Funding Contract no. 42/05.09.2016.

\section{References}

1. Sim W.M. (2009): Deliverable 1.1.10-Publishable Final Activity Report. COMPACT publishable report submitted to the European Commission

2. Withers P.J., Bhadeshia H.K.D.H. (2001): Residual stress-II: nature and origins. Mater Sci Tech, p-ISSN 0267-0836, e-ISSN 1743-2847, Vol. 17, pp. 366-375, https://doi.org/10.1179/026708301101510087

3. Milkereit B., Starink M.J., Rometsch P.A., Schick C., Kessler 0. (2019): Review of the Quench Sensitivity of Aluminium Alloys: Analysis of the Kinetics and Nature of Quench-Induced Precipitation. Materials (Basel), ISSN 1996-1944, 12(24):4083, https://doi.org/10.3390/ma12244083

4. Prime M.B., Hill M.R. (2002): Residual stress, stress relief, and inhomogeneity in aluminum plate. Scripta Materialia, ISSN 1359-6462, Vol. 46, is. 1, pp. 77-82, https://doi.org/10.1016/S1359-6462(01)01201-5

5. Robinson J.S., Tanner D.A., Truman C.E. (2014): The origin and management of residual stress in heat-treatable aluminium alloys. Strain, e-ISSN 1475-1305, Vol. 50, pp.185-207, https://doi.org/10.1111/str.12091

6. Li J.-g., Wang S.-q. (2017): Distortion caused by residual stresses in machining aeronautical aluminum alloy parts: recent advances. Int J Adv Manuf Technol, Vol. 89, pp. 997-1012, https://doi.org/10.1007/s00170-016-9066-6 
7. Hossain M.M.A. Rashed (2018): Control of Distortion in Aluminium Heat Treatment. Chapter 13 in: Lumley R.N., Fundamentals of Aluminium Metallurgy, Woodhead Publishing, ISBN 9780081020630, pp 495-524, https://doi.org/10.1016/B978-0-08-102063-0.00013-8

8. Mackerle J. (2003): Finite element analysis and simulation of quenching and other heat treatment processes: $A$ bibliography (1976-2001). Computational Materials Science, ISSN 0927-0256, Vol. 27, is. 3, pp. 313-332, https://doi.org/10.1016/S0927-0256(03)00038-7

9. Şimşir C. (2008): 3D finite element simulation of steel quenching in order to determine the microstructure and residual stresses. PhD thesis, Middle East Technical University, Ankara, Turkey, http://etd.lib.metu. edu.tr/upload/12609412/index.pdf

10. Petre M. et al (2020): Mathematical Modelling of the Quenching Process of 6061 Aluminium Alloy Plates. Int. Conf. on Applied Mathematics and Numerical Methods (ICAMNM) - $3^{\text {rd }}$ ed., Craiova, Romania

11. Summers P.T. et al (2015): Overview of aluminum alloy mechanical properties during and after fires. Fire Science Reviews, e-ISSN 2193-0414, Vol. 4, is. 3, https://doi.org/10.1186/s40038-015-0007-5

12. *** (1990): ASM Handbook Vol. 2. Properties and Selection: Nonferrous Alloys and Special - Purpose Materials. ASM International, ISBN 978-0-87170-378-1

13. Wolberg J. (2006): Data Analysis Using the Method of Least Squares: Extracting the Most Information from Experiments. Springer, ISBN 978-3-540-25674-8, eBook ISBN 978-3-540-31720-3

14. Santos M.C. Jr., Machado A.R., Sales W.F., Barrozo M.A.S., Ezugwu E.O. (2016): Machining of aluminum alloys: $a$ review. Int J Adv Manuf Technol, Vol. 86, pp. 3067-3080, https://doi.org/10.1007/s00170-016-8431-9

15. Masoudi S., Amini S., Saeidi E., Eslami-Chalander H. (2015): Effect of machining-induced residual stress on the distortion of thin-walled parts. Int J Adv Manuf Technol, p-ISSN 0268-3768, e-ISSN 1433-3015, Vol. 76, pp. 597-608, https://doi.org/10.1007/s00170-014-6281-x 